\title{
REVIEW
}

\section{Current and Emerging Medical Therapies for Primary Hyperhidrosis}

Daniel A. Grabell · Adelaide A. Hebert

Received: August 16, 2016 / Published online: October 27, 2016

(C) The Author(s) 2016. This article is published with open access at Springerlink.com

\begin{abstract}
Hyperhidrosis is defined as the production of sweat beyond what is physiologically necessary to maintain thermal homeostasis. This disease state may (and typically does) have a significant impact on the patient's quality of life. Medications including antiperspirants, anticholinergics, and botulinum toxin have been shown to be effective in the management of hyperhidrosis. Several medical device technologies have also proven to be effective. This review article will explore the current and emerging pharmacological and medical device treatments for hyperhidrosis and provide a framework for treating patients who suffer with primary forms of hyperhidrosis.
\end{abstract}

Enhanced content To view enhanced content for this article go to http://www.medengine.com/Redeem/ 9AF6F0600CBA195E.

D. A. Grabell · A. A. Hebert ( $₫)$

Department of Dermatology, UTHealth McGovern

Medical School, Houston, TX, USA

e-mail: adelaide.a.hebert@uth.tmc.edu

A. A. Hebert

Department of Pediatrics, UTHealth McGovern

Medical School, Houston, TX, USA
Keywords: Aluminum chloride; Botulinum toxin; Emerging therapies; Hyperhidrosis; Iontophoresis

\section{INTRODUCTION}

Hyperhidrosis is defined as the production of sweat beyond what is physiologically necessary to maintain thermal homeostasis. This condition can be categorized as primary (idiopathic) or secondary (related to a known cause). Several studies have estimated that $1.6-2.9 \%$ of the United States population have been affected by primary hyperhidrosis [1-7]. One study conducted outside the United States has reported a prevalence as high as $16.3 \%$ of the population [3]. The pathophysiology of this disorder is poorly understood but primary hyperhidrosis has been postulated to have a genetic component. Studies have shown that $65 \%$ of patients with a diagnosis of primary focal hyperhidrosis reported a family history of the disease [8]. A genome-wide linkage analysis showed that chromosome $14 \mathrm{q}$ is possibly associated with hyperhidrosis [9]. This disease state likely represents a dysregulation involving both the 
sympathetic and parasympathetic nervous systems $[10,11]$.

The diagnosis of primary focal hyperhidrosis is made via the history and physical examination with a focus on the consensus conference diagnostic criteria. The criteria require at least a 6-month history of focal and visible sweating without secondary causes [12]. In addition, at least two of the following criteria must be met: bilateral and symmetric hyperhidrosis, impairment of activities of daily living, onset at age less than 25 years old, at least one episode per week, family history of the disease, or an absence of symptoms during sleep [12]. Exclusion of medications that can cause hyperhidrosis including anticholinesterases, selective serotonin reuptake inhibitors, tricyclic antidepressants, glaucoma agents, bladder stimulants, opioids, and sialagogues remains essential to ensure proper diagnosis [13]. The marked impact of primary hyperhidrosis on a patient's quality of life has been measured in clinical trials using the validated Hyperhidrosis Disease Severity Scale [14-16]. Treatment of hyperhidrosis has focused on improving symptoms, reduction of the sweat and its inherent socially stigmatizing impact, and subsequently improving the quality of life of the patients [1]. The objective of this article is to explore the current and emerging pharmacological and medical device treatments for hyperhidrosis and to provide a framework for treating patients. Surgical options including curettage, skin excision, and sympathetic block for hyperhidrosis will be covered in a separate paper.

\section{METHODS}

A search regarding current treatments was conducted through 5 July 2016 using PubMed,
The Cochrane Library, Google Scholar, Clinical Key, and Embase. The following keywords were used to research the literature for references: "hyperhidrosis", "primary hyperhidrosis", "primary focal hyperhidrosis", "sweating", "excessive sweating", "treatments for hyperhidrosis", and "treatments for excessive sweating". All relevant English-language literature was reviewed, and the reference list of articles of interest were reviewed for further citations. In addition, clinicaltrials.gov was also searched using the criteria "hyperhidrosis", and subsequent literature searches were made on all new compounds and devices being developed.

This article is a review of existing data from previously conducted studies that are publically available and does not involve any new studies of animals or human subjects performed by the authors.

\section{CURRENT THERAPIES FOR HYPERHIDROSIS}

Current therapies for hyperhidrosis are divided into several categories including topical, oral, and injectable medications and medical devices.

\section{Topical Therapies}

Antiperspirants which usually contain aluminum salts are the first-line treatment for hyperhidrosis because of their safety profile, cost-effectiveness, and efficacy [17-19]. Preparations in the United States can vary in the amount of metal salts up to $25 \%$ depending on the aluminum compound used [20]. Antiperspirants are believed to work by obstructing the distal eccrine sweat gland ducts $[19,21]$. Patients with hyperhidrosis who use these products may develop miliaria due to the ongoing production of sweat inferior to the 
blocked sweat duct, but long-term blockage may lead to functional and structural degeneration of the eccrine acini which does not cause harm to the patient in the process of reducing sweat production [21].

A case series published by Scholes et al., in which 65 patients treated with 20\% aluminum chloride hexahydrate topically nightly for 1 week, then as needed, showed that patients reported complete control of axillary sweating. After initial treatment, most patients applied the substance every 7-21 days which correlated with epidermal renewal [22, 23]. Aluminum chloride hexahydrate has been shown to be effective in palmar hyperhidrosis in a clinical trial that reported decreased skin water vapor loss; however, the effect disappeared $48 \mathrm{~h}$ after stopping treatment [19]. Additionally a 6-week randomized trial of 12 patients showed that aluminum chloride hexahydrate $12.5 \%$ was equally as effective as $30 \%$ for the treatment of plantar hyperhidrosis [24].

Many patients achieve satisfactory results with aluminum chloride compounds. In a study of 691 patients treated with aluminum chloride solutions, $82 \%$ achieved satisfying results with either complete resolution or a level of sweating perceived as normal after initial treatment. In a long-term follow-up study of these patients, satisfaction levels increased to $87 \%$ with patients using maintenance therapy [23].

Skin irritation is a common limiting adverse event with aluminum chloride hexahydrate. The irritation occurs when the compound is applied to moist skin allowing the formation of weak hydrochloric acid [25]. In one study, 36\% of all patients reported moderate irritation and $14 \%$ reported severe irritation [23]. Other adverse effects include itching and stinging on application which improved with continual usage [23]. Some studies have shown that application of a low-potency steroid, such as topical hydrocortisone, in the morning can decrease irritation [22, 26]. Applying aluminum chloride hexahydrate to completely dry skin greatly reduces the risk of focal skin irritation [25]. To ensure the skin is dry, some clinicians have recommended avoiding washing the axillae prior to the application of aluminum chloride hexahydrate, drying the axillae with a blow dryer on a cool setting, or applying the medication at nighttime and removing it in the morning [25].

Topical glycopyrrolate $2 \%$ is a medication believed to improve hyperhidrosis through its anticholinergic properties by competitively binding the muscarinic acetylcholine receptors [27]. Several case reports and a few randomized trials have been conducted to evaluate its efficacy in facial hyperhidrosis. One study of 25 patients with facial hyperhidrosis showed that $96 \%$ were partially or fully satisfied with the results of the medication [28]. Another study of 39 patients with facial hyperhidrosis showed a reduction of sweat production on the forehead of $25 \% 90 \mathrm{~min}$ after application with no significant improvement in the Hyperhidrosis Disease Severity Scale [29]. However, the results in axillary hyperhidrosis have been less clinically meaningful. An uncontrolled study of 35 patients with axillary hyperhidrosis who had failed aluminum chloride hexahydrate therapy was unable to show a consistent and meaningful benefit from glycopyrrolate compounded in Cetomacrogol Cream BP [30]. Glycopyrrolate may be used topically twice daily although some authors recommend applying it nightly [31]. Patients should be advised to avoid the nose, mouth, and eyes as the anticholinergic properties can prevent ocular accommodation [31].

Formaldehyde and glutaraldehyde are not commonly used in the treatment of primary focal hyperhidrosis, as these agents can cause 
localized skin irritation, allergic sensitization, and central nervous system toxicity [25, 32].

\section{Oral Therapies}

Oral anticholinergics are a potential treatment for hyperhidrosis but are occasionally limited by the side effect profile. A retrospective chart review of 45 patients with hyperhidrosis who were prescribed glycopyrrolate showed a $67 \%$ response rate with 6 patients not responding to treatment and 9 patients discontinuing therapy secondary to developing adverse events including dry mouth and gastrointestinal disturbances [33]. A retrospective chart review in children has shown improvement in $90 \%$ of all patients, with the most common side effects being dry mouth (26\%) and dry eyes (10\%) [34]. Oxybutinin, a competitive antagonist at the postganglionic muscarinic receptors, is another potential treatment for hyperhidrosis. A prospective, randomized, placebo-controlled trial for the initial treatment of hyperhidrosis showed improvement in greater than $70 \%$ of patients with palmar and axillary hyperhidrosis and greater than $90 \%$ of patients with plantar hyperhidrosis [35]. A subsequent study showed a 60\% improvement in the Hyperhidrosis Disease Severity Scale and a significant improvement in the Dermatology Life Quality Index [36]. Dosing in the literature varies greatly from 2.5 to $5 \mathrm{mg}$ twice daily with dry mouth being the main dose-limiting adverse event $[35,37]$. Bornaprine is an oral anticholinergic with limited commercial availability which has been studied in hyperhidrosis; however, the central nervous system adverse events limit the usage of this medication [38].

Other oral medications have been suggested to be effective in hyperhidrosis but have limited data and are of limited value given the availability of alternative therapies. These include beta-blockers, benzodiazepines, methanthelinium bromide, and clonidine. Beta-blockers, in particular propranolol, and benzodiazepines, have been reported to be successful in hyperhidrosis if the patient is believed to have an anxiety trigger [39]. Oral methanthelinium bromide $50 \mathrm{mg}$ was compared in a randomized trial which showed a mean decrease in axillary sweat production of $69 \mathrm{mg}$ in $5 \mathrm{~min}$; however, no significant difference was seen in palmar sweat production [40]. Two case reports have shown that clonidine $0.2-0.4 \mathrm{mg}$ is effective in reducing craniofacial hyperhidrosis [41].

\section{Injectable Therapies}

Botulinum toxin is an acetylcholine release inhibitor and a neuromuscular blocking agent that is commercially available in the United States [42, 43]. Each botulinum toxin (OnabotulinumtoxinA, AbobotulinumtoxinA, and IncobotulinumtoxinA) has different characteristics with variable clinical equipotency ratios that are influenced by the severity of the underlying disease [44]. A multicenter, randomized, parallel group, placebo-controlled trial of 320 patients evaluated OnabotulinumtoxinA for axillary hyperhidrosis with a primary endpoint of a greater than or equal to 50\% reduction in baseline spontaneous axillary sweat production [45]. At 4 weeks, 94\% of patients on active treatment had met this endpoint, with $82 \%$ maintaining this endpoint at week 16 [45]. Patients who respond to treatment can have consistent reduction of axillary sweat for greater than 5 months with repeat dosing shown to be safe with equal or potentially increased efficacy [46-48].

Other types of botulinum toxin have limited data available. Efficacy appears equal between 150 units of AbobotulinumtoxinA and 50 units 
of OnabotulinumtoxinA per axilla; however, other studies have shown no difference between 100 and 200 units of AbobotulinumtoxinA $[49,50]$. Several other studies have validated a variety of types of botulinum toxin for palmar and plantar hyperhidrosis [48, 51-57].

The administration of botulinum toxin requires multiple injections spaced approximately $2 \mathrm{~cm}$ apart which can pose many challenges, most notably pain at the injection site. In order to reduce pain from multiple injections, several studies have evaluated different techniques such as using ice, topical anesthetics, or diluting the botulinum toxin with lidocaine. The use of ice packs has been shown to decrease the discomfort associated with the multiple needle injections, and this methodology is cost-effective and non-threatening to patients [58-60]. Another cost-effective form of anesthesis is vibration, which has been shown to reduce patient discomfort during botulinum injections [61]. Other clinicians have advocated for topical anesthetics such as tetracaines or lidocaine/ prilocaine cream which have been shown to be effective but need to be applied $45 \mathrm{~min}$ prior to the procedure $[62,63]$. Some studies have even shown that diluting OnabotulinumtoxinA with lidocaine instead of normal saline decreases pain without a loss of efficacy [64, 65]. For patients with palmar hyperhidrosis who cannot tolerate a cooling technique, an ulnar, median, and radial nerve block or a modified Bier Block can be effective [66-69].

\section{Medical Device Therapies}

Iontophoresis, the passing of an ionized substance through intact skin, is a treatment method that delivers 15-20 milliamps of current through tap-water to treat hyperhidrosis $[70,71]$. The exact mechanism of action is unclear, but several hypotheses exist including the inhibition of sympathetic nerve transmission, ion deposition obstructing the sweat gland, and local alterations of $\mathrm{pH}$ inhibiting the sweat gland [72-75]. Initial treatment of 8 sessions in a 28 -day period showed a $81 \%$ reduction in sweat with maintenance therapy required to maintain the effect [76]. Common adverse events include discomfort, vesiculation, and erythema [77]. The impact of iontophoresis can be enhanced if glycopyrrolate pills are added to the trays before the iontophoresis is initiated [27, 78-81]. At least two companies, Hidrex http://www.hidrexusa. com/ and R.A. Fisher and Co http://www. rafischer.com/cat_iontophoresis in the United States, offer iontophoresis units for either sale or rental.

Microwave thermolysis has also been shown to be an effective treatment for hyperhidrosis. Microwaves heat by physical rotations of molecules with high dipole moment such as the ionic water in eccrine glands while avoiding low dipole moment molecules such as fat [16]. A study of a device using this technique in axillary hyperhidrosis showed a $89 \%$ response rate after treatment with $69 \%$ maintaining the effect at 12 months [16]. Adverse events include temporary tenderness, swelling, and numbness [82].

\section{Adjunctive Therapies}

In addition to pharmaceutical and medical device therapies, several adjunctive therapies can be helpful to patients. Educating the patient about the disease state and showing empathy are critical to increasing compliance with regimens. The International Hyperhidrosis Society hosts a website http://www.sweathelp. org which can serve as a resource for patient education on the disease state and treatment options. In addition, several companies with links on the website offer specialized shirts, 
socks and other footwear that can wick moisture away and prevent wet marks and stains. To help patients sleep better, moisture-wicking bed sheets are also available.

\section{EMERGING THERAPIES FOR HYPERHIDROSIS}

Despite many approved therapies, there is still an unmet need for more effective and convenient methods for managing hyperhidrosis.

\section{Topical Therapies}

Several topical anticholinergic agents are currently in development for hyperhidrosis. Oxybutynin, which has been used off-label for hyperhidrosis in an oral formulation, is frequently associated with anticholinergic adverse events including dry mouth [83]. The adverse events are believed to be caused by an active metabolite $N$-desethyloxybutynin [84]. As a result, a transdermal gel formulation was approved in the US for overactive bladder. This gel reduces the anticholinergic adverse events associated with oral oxybutynin by avoiding gastrointestinal and hepatic first pass metabolism which reduces the level of the active metabolite [84-86]. A study is currently underway to evaluate oxybutynin gel in patients with axillary hyperhidrosis. Studies are also being conducted on umeclidinium, glycopyrrolate tosylate, and sofpironium bromide, but limited information is currently available in peer-reviewed journals.

\section{Medical Device Therapies}

Several medical device therapies are currently in development including radiofrequency thermotherapy, laser therapy, and ultrasound therapy. Radiofrequency thermotherapy is a minimally invasive therapy which utilizes a device to insert microneedles into the skin and emit bipolar thermal energy [87]. By focusing the energy with microneedles, the thermotherapy is directed to the eccrine sweat glands in the dermis with minimal trauma to the epidermis [87]. The efficacy of fractional microneedle radiofrequency thermotherapy has been shown in small randomized control trials to significantly improve the Hyperhidrosis Disease Severity Score as well as decrease sweat production [87-89]. In addition, histopathologic findings have shown a decrease in the number of sweat glands in tissue [89]. One study that followed patients for 1 year found that overweight patients may need additional treatments to maintain the effect [90].

Several different types of lasers have been studied to reduce sweat production with limited and inconsistent results to date. In a prospective case-control study of the YAG 1064-nm laser, a modified starch iodine test showed effective improvement at 9 months; however, no significant difference in eccrine glands was seen in pre- and post-treatment biopsies of the axillary skin [91]. A study of 21 patients with axillary hyperhidrosis using the 800-nm diode laser with a half-side control design showed a decrease in the sweat rate on the laser-treated sites but not statistically significantly more than on the untreated site [92]. A randomized control trial of 100 patients utilizing the 924and 975-nm lasers simultaneously showed an improvement in the Hyperhidrosis Disease Severity Score and the modified starch iodine test at 1 and 12 months of follow-up [93]. Studies of the 1210-nm laser and the 1440-nm laser for hyperhidrosis are currently being conducted.

Ultrasound technology is another method to selectively target the glandular tissue for the 
treatment of hyperhidrosis. In a randomized double-blind, sham-controlled study of 12 patients with axillary hyperhidrosis utilizing micro-focused ultrasound with visualization, $83 \%$ of all patients experienced a greater than or equal to $50 \%$ reduction in sweat production as measured using a gravimetric assessment [94]. In this study, patients followed for 12 months showed long-lasting effects [94]. Another study utilizing the VASER showed that 11 out of 13 patients had a significant reduction in sweat production and odor without recurrence in 6 months [95]. In addition, ultrasound has been reported to have been used to induce a therapeutic stellate ganglion block in a patient with efficacy for at least a few weeks [96].

\section{DISCUSSION}

Hyperhidrosis is a disorder of excess sweat production which can have a dramatic impact on a patient's quality of life. The disease state appears to have a genetic component, given the presence of a family history. Hyperhidrosis likely represents a dysregulation of the sympathetic and parasympathetic systems. More research is needed to better understand the true pathophysiology of the disease process.

A number of topical, oral, and injectable options are available to treat hyperhidrosis. Topical antiperspirants are the first-line agent and are best applied on a dry surface to prevent irritation of the skin. Second-line agents and strategies include oxybutynin, botulinum toxin, and iontophoresis. Oxybutynin has been shown to be an effective oral medication which improves the quality of life in patients with hyperhidrosis; however, dry mouth is a common adverse event that may limit the usage of the medication. Topical formulation of anticholinergics, including oxybutynin, are likely to have similar efficacy with less systemic adverse effects. Injectable botulinum toxin has also been shown to be effective, but the cost and pain associated with multiple injections can be limiting factors. Utilizing cooling agents, diluting the botulinum toxin in lidocaine, and performing a nerve block are all effective methods to reduce the pain.

Many medical device options are currently used or are in development for hyperhidrosis. Iontophoresis is a proven method which works best on palmar and plantar surfaces and can be enhanced with the addition of glycopyrrolate. Microwave technology has been shown to be effective with a long-lasting effect. Several lasers have been studied in hyperhidrosis patients; however, the results to date have been quite mixed and the role in treating hyperhidrosis remains unclear. Microneedle radiofrequency and ultrasound technology are promising new methods of treatment allowing for a focused area of thermotherapy targeting the eccrine sweat glands and potentially developing a long-term treatment.

\section{CONCLUSION}

Clinicians have many effective pharmacological and medical device options in treating patients with hyperhidrosis. While no guidelines exist in the United States, the Canadian Hyperhidrosis Advisory Committee has developed treatment algorithms for clinicians to follow [97]. Many more therapies are currently in development. Utilizing the best treatment along with education and empathy will increase a patient's compliance and lead to a meaningful clinical outcome. 


\section{ACKNOWLEDGMENTS}

No funding or sponsorship was received for this study or publication of this article. All authors had full access to all of the data in this study and take complete responsibility for the integrity of the data and accuracy of the data analysis. No medical writing or editorial assistance was received in the preparation of this manuscript. All named authors meet the International Committee of Medical Journal Editors (ICMJE) criteria for authorship for this manuscript, take responsibility for the integrity of the work as a whole, and have given final approval for the version to be published.

Disclosures. A.A. Hebert received grant funding from Allergan in 2005-2007 to conduct research on Botox in hyperhidrosis and all grant funding was paid to the UT Medical School-Houston. D.A. Grabell has nothing to disclose.

Compliance with Ethics Guidelines. This article is a review of existing data from previously conducted studies that are publically available and does not involve any new studies of animals or human subjects performed by the authors.

Open Access. This article is distributed under the terms of the Creative Commons Attribution-NonCommercial 4.0 International License (http://creativecommons.org/licenses/ by-nc/4.0/), which permits any noncommercial use, distribution, and reproduction in any medium, provided you give appropriate credit to the original author(s) and the source, provide a link to the Creative Commons license, and indicate if changes were made.

\section{REFERENCES}

1. Strutton DR, Kowalski JW, Glaser DA, Stang PE. US prevalence of hyperhidrosis and impact on individuals with axillary hyperhidrosis: results from a national survey. J Am Acad Dermatol. 2004;51(2):241-8.

2. Moraites E, Vaughn OA, Hill S. Incidence and prevalence of hyperhidrosis. Dermatol Clin. 2014;32(4):457-65.

3. Augustin M, Radtke MA, Herberger K, Kornek T, Heigel H, Schaefer I. Prevalence and disease burden of hyperhidrosis in the adult population. Dermatology. 2013;227(1):10-3.

4. Liu Y, Bahar R, Kalia S, Huang RY, Phillips A, Su M, et al. Hyperhidrosis prevalence and demographical characteristics in dermatology outpatients in Shanghai and Vancouver. PLOS ONE. 2016;11(4):e0153719.

5. Lai FC, Tu YR, Li YP, Li X, Lin M, Chen JF, et al. Nation wide epidemiological survey of primary palmar hyperhidrosis in the People's Republic of China. Clin Auton Res. 2015;25(2):105-8.

6. Adar R, Kurchin A, Zweig A, Mozes M. Palmar hyperhidrosis and its surgical treatment: a report of 100 cases. Ann Surg. 1977;186(1):34-41.

7. Leung AK, Chan PY, Choi MC. Hyperhidrosis. Int J Dermatol. 1999;38(8):561-7.

8. Ro KM, Cantor RM, Lange KL, Ahn SS. Palmar hyperhidrosis: evidence of genetic transmission. J Vasc Surg. 2002;35(2):382-6.

9. Higashimoto I, Yoshiura $\mathrm{K}$, Hirakawa N, Higashimoto $\mathrm{K}$, Soejima $\mathrm{H}$, Totoki $\mathrm{T}$, et al. Primary palmar hyperhidrosis locus maps to 14q11.2-q13. Am J Med Genet A. 2006;140(6):567-72.

10. Shih CJ, Wu JJ, Lin MT. Autonomic dysfunction in palmar hyperhidrosis. J Auton Nerv Syst. 1983;8(1):33-43.

11. Birner P, Heinzl H, Schindl M, Pumprla J, Schnider P. Cardiac autonomic function in patients suffering from primary focal hyperhidrosis. Eur Neurol. 2000;44(2):112-6.

12. Hornberger J, Grimes K, Naumann M, Glaser DA, Lowe NJ, Naver H, et al. Recognition, diagnosis, and treatment of primary focal hyperhidrosis. J Am Acad Dermatol. 2004;51(2):274-86. 
13. Cheshire WP, Fealey RD. Drug-induced hyperhidrosis and hypohidrosis: incidence, prevention and management. Drug Saf. 2008;31(2):109-26.

14. Cina CS, Clase CM. The Illness Intrusiveness Rating Scale: a measure of severity in individuals with hyperhidrosis. Qual Life Res. 1999;8(8):693-8.

15. Amir M, Arish A, Weinstein Y, Pfeffer M, Levy Y. Impairment in quality of life among patients seeking surgery for hyperhidrosis (excessive sweating): preliminary results. Isr J Psychiatry Relat Sci. 2000;37(1):25-31.

16. Glaser DA, Coleman WP 3rd, Fan LK, Kaminer MS, Kilmer SL, Nossa R, et al. A randomized, blinded clinical evaluation of a novel microwave device for treating axillary hyperhidrosis: the dermatologic reduction in underarm perspiration study. Dermatol Surg. 2012;38(2):185-91.

17. Shelley WB, Hurley HJ Jr. Studies on topical antiperspirant control of axillary hyperhidrosis. Acta Derm Venereol. 1975;55(4):241-60.

18. Brandrup F, Larsen PO. Axillary hyperhidrosis: local treatment with aluminum chloride hexahydrate $25 \%$ in absolute ethanol. Acta Derm Venereol. 1978;58(5):461-5.

19. Goh CL. Aluminum chloride hexahydrate versus palmar hyperhidrosis. Evaporimeter assessment. Int J Dermatol. 1990;29(5):368-70.

20. CFR-Code of Federal Regulations Title 21 Washington D.C. 2015 [updated Apr 1, 2015; cited July 5, 2016]. http://www.accessdata.fda.gov/ scripts/cdrh/cfdocs/cfcfr/cfrsearch.cfm?fr=350.10.

21. Holzle E, Braun-Falco O. Structural changes in axillary eccrine glands following long-term treatment with aluminium chloride hexahydrate solution. Br J Dermatol. 1984;110(4):399-403.

22. Scholes KT, Crow KD, Ellis JP, Harman RR, Saihan EM. Axillary hyperhidrosis treated with alcoholic solution of aluminium chloride hexahydrate. $\mathrm{Br}$ Med J. 1978;2(6130):84-5.

23. Hölzle E. Topical pharmacological treatment. Curr Probl Dermatol. 2002;30:30-43.

24. Streker M, Reuther T, Hagen L, Kerscher M. Hyperhidrosis plantaris-a randomized, half-side trial for efficacy and safety of an antiperspirant containing different concentrations of aluminium chloride. J Dtsch Dermatol Ges. 2012;10(2):115-9.

25. White JW Jr. Treatment of primary hyperhidrosis. Mayo Clin Proc. 1986;61(12):951-6.
26. Stolman LP. Treatment of hyperhidrosis. Dermatol Clin. 1998;16(4):863-9.

27. Bajaj V, Langtry JA. Use of oral glycopyrronium bromide in hyperhidrosis. $\mathrm{Br} \mathrm{J}$ Dermatol. 2007;157(1):118-21.

28. Kim WO, Kil HK, Yoon KB, Yoon DM. Topical glycopyrrolate for patients with facial hyperhidrosis. Br J Dermatol. 2008;158(5):1094-7.

29. Hyun MY, Son IP, Lee Y, Choi HG, Park KY, Li K, et al. Efficacy and safety of topical glycopyrrolate in patients with facial hyperhidrosis: a randomized, multicentre, double-blinded, placebo-controlled, split-face study. J Eur Acad Dermatol Venereol. 2015;29(2):278-82.

30. Mackenzie A, Burns C, Kavanagh G. Topical glycopyrrolate for axillary hyperhidrosis. $\mathrm{Br} J$ Dermatol. 2013;169(2):483-4.

31. Kavanagh GM, Burns C, Aldridge RD. Topical glycopyrrolate should not be overlooked in treatment of focal hyperhidrosis. Br J Dermatol. 2006;155(2):487.

32. Songur A, Ozen OA, Sarsilmaz M. The toxic effects of formaldehyde on the nervous system. Rev Environ Contam Toxicol. 2010;203:105-18.

33. Walling HW. Systemic therapy for primary hyperhidrosis: a retrospective study of 59 patients treated with glycopyrrolate or clonidine. J Am Acad Dermatol. 2012;66(3):387-92.

34. Paller AS, Shah PR, Silverio AM, Wagner A, Chamlin SL, Mancini AJ. Oral glycopyrrolate as second-line treatment for primary pediatric hyperhidrosis. J Am Acad Dermatol. 2012;67(5):918-23.

35. Wolosker N, de Campos JR, Kauffman P, Puech-Leao P. A randomized placebo-controlled trial of oxybutynin for the initial treatment of palmar and axillary hyperhidrosis. J Vasc Surg. 2012;55(6):1696-700.

36. Schollhammer M, Brenaut E, Menard-Andivot N, Pillette-Delarue M, Zagnoli A, Chassain-Le Lay M, et al. Oxybutynin as a treatment for generalized hyperhidrosis: a randomized, placebo-controlled trial. Br J Dermatol. 2015;173(5):1163-8.

37. Costa Ada S Jr, Leao LE, Succi JE, Perfeito JA, Filho Castelo A, Rymkiewicz E, et al. Randomized trialoxybutynin for treatment of persistent plantar hyperhidrosis in women after sympathectomy. Clinics (Sao Paulo). 2014;69(2):101-5.

38. Sergi R, Massone A, Moretto S, Oggerino C, Bertolotto F, Losio L, et al. Hyperhidrosis treatment with bornaprine in the acute phase of 
spinal cord-injured patients. Spinal Cord. 2008;46(8):571-3.

39. Glaser DA. Oral medications. Dermatol Clin. 2014;32(4):527-32.

40. Muller C, Berensmeier A, Hamm H, Dirschka T, Reich $\mathrm{K}$, Fischer $\mathrm{T}$, et al. Efficacy and safety of methantheline bromide (Vagantin((R))) in axillary and palmar hyperhidrosis: results from a multicenter, randomized, placebo-controlled trial. J Eur Acad Dermatol Venereol. 2013;27(10):1278-84.

41. Torch EM. Remission of facial and scalp hyperhidrosis with clonidine hydrochloride and topical aluminum chloride. S Med J. 2000;93(1):68-9.

42. Aoki KR, Guyer B. Botulinum toxin type A and other botulinum toxin serotypes: a comparative review of biochemical and pharmacological actions. Eur J Neurol. 2001;8(Suppl 5):21-9.

43. Esquenazi A, Albanese A, Chancellor MB, Elovic E, Segal KR, Simpson DM, et al. Evidence-based review and assessment of botulinum neurotoxin for the treatment of adult spasticity in the upper motor neuron syndrome. Toxicon. 2013;67:115-28.

44. Bentivoglio AR, Del Grande A, Petracca M, Ialongo $\mathrm{T}$, Ricciardi L. Clinical differences between botulinum neurotoxin type $\mathrm{A}$ and $\mathrm{B}$. Toxicon. 2015;107(Pt A):77-84.

45. Naumann M, Lowe NJ. Botulinum toxin type A in treatment of bilateral primary axillary hyperhidrosis: randomised, parallel group, double blind, placebo controlled trial. BMJ. 2001;323(7313):596-9.

46. Odderson IR. Long-term quantitative benefits of botulinum toxin type A in the treatment of axillary hyperhidrosis. Dermatol Surg. 2002;28(6):480-3.

47. Naumann M, Lowe NJ, Kumar CR, Hamm H, Hyperhidrosis Clinical Investigators G. Botulinum toxin type $\mathrm{a}$ is a safe and effective treatment for axillary hyperhidrosis over 16 months: a prospective study. Arch Dermatol. 2003;139(6):731-6.

48. Lecouflet M, Leux C, Fenot M, Celerier P, Maillard $H$. Duration of efficacy increases with the repetition of botulinum toxin A injections in primary palmar hyperhidrosis: a study of 28 patients. J Am Acad Dermatol. 2014;70(6):1083-7.

49. Talarico-Filho S, Mendonca DONM, Sperandeo DEMF, C DESP. A double-blind, randomized, comparative study of two type A botulinum toxins in the treatment of primary axillary hyperhidrosis. Dermatol Surg. 2007;33(1 Spec No.):S44-50.
50. Heckmann M, Plewig G, Hyperhidrosis Study G. Low-dose efficacy of botulinum toxin A for axillary hyperhidrosis: a randomized, side-by-side, open-label study. Arch Dermatol. 2005;141(10):1255-9.

51. Rystedt A, Swartling C, Farnstrand C, Naver H. Equipotent concentrations of Botox and Dysport in the treatment of palmar hyperhidrosis. Acta Derm Venereol. 2008;88(5):458-61.

52. Saadia D, Voustianiouk A, Wang AK, Kaufmann H. Botulinum toxin type $A$ in primary palmar hyperhidrosis: randomized, single-blind, two-dose study. Neurology. 2001;57(11):2095-9.

53. Simonetta Moreau M, Cauhepe C, Magues JP, Senard JM. A double-blind, randomized, comparative study of dysport vs. botox in primary palmar hyperhidrosis. Br J Dermatol. 2003;149(5):1041-5.

54. Schnider P, Binder M, Auff E, Kittler H, Berger T, Wolff K. Double-blind trial of botulinum A toxin for the treatment of focal hyperhidrosis of the palms. Br J Dermatol. 1997;136(4):548-52.

55. Lowe NJ, Yamauchi PS, Lask GP, Patnaik R, Iyer S. Efficacy and safety of botulinum toxin type a in the treatment of palmar hyperhidrosis: a double-blind, randomized, placebo-controlled study. Dermatol Surg. 2002;28(9):822-7.

56. D’Epiro S, Macaluso L, Salvi M, Luci C, Mattozzi C, Marzocca F, et al. Safety and prolonged efficacy of botulin toxin A in primary hyperhidrosis. Clin Ter. 2014;165(6):e395-400.

57. Weinberg T, Solish N, Murray C. Botulinum neurotoxin treatment of palmar and plantar hyperhidrosis. Dermatol Clin. 2014;32(4):505-15.

58. Kuwahara RT, Skinner RB. Emla versus ice as a topical anesthetic. Dermatol Surg. 2001;27(5):495-6.

59. Dixit S, Lowe P, Fischer G, Lim A. Ice anaesthesia in procedural dermatology. Australas J Dermatol. 2013;54(4):273-6.

60. Patel R, Halem M, Zaiac M. The combined use of forced cold air and topical anesthetic cream for analgesia during the treatment of palmar hyperhydrosis with botulinum toxin injections. J Drugs Dermatol. 2009;8(10):948-51.

61. Sharma P, Czyz CN, Wulc AE. Investigating the efficacy of vibration anesthesia to reduce pain from cosmetic botulinum toxin injections. Aesthet Surg J. 2011;31(8):966-71.

62. O'Riordan JM, Fitzgerald E, Gowing C, O'Grady H, Feeley TM, Tierney S. Topical local anaesthetic 
(tetracaine) reduces pain from botulinum toxin injections for axillary hyperhidrosis. $\mathrm{Br} \mathrm{J}$ Surg. 2006;93(6):713-4.

63. Elibol O, Ozkan B, Hekimhan PK, Caglar Y. Efficacy of skin cooling and EMLA cream application for pain relief of periocular botulinum toxin injection. Ophthal Plast Reconstr Surg. 2007;23(2):130-3.

64. Gulec AT. Dilution of botulinum toxin A in lidocaine vs. in normal saline for the treatment of primary axillary hyperhidrosis: a double-blind, randomized, comparative preliminary study. J Eur Acad Dermatol Venereol. 2012;26(3):314-8.

65. Vadoud-Seyedi J, Simonart T. Treatment of axillary hyperhidrosis with botulinum toxin type A reconstituted in lidocaine or in normal saline: a randomized, side-by-side, double-blind study. Br J Dermatol. 2007;156(5):986-9.

66. Solomon P. Modified Bier block anesthetic technique is safe for office use for botulinum a toxin treatment of palmar and plantar hyperhidrosis. Dermatol Online J. 2007;13(3):6.

67. Ponce-Olivera RM, Tirado-Sanchez A, Arellano-Mendoza MI, Leon-Dorantes G, Kassian-Rank S. Palmar hyperhidrosis. Safety efficacy of two anaesthetic techniques for botulinum toxin therapy. Dermatol Online J. 2006;12(2):9.

68. de Almeida AR, Kadunc BV, de Oliveira EM. Improving botulinum toxin therapy for palmar hyperhidrosis: wrist block and technical considerations. Dermatol Surg. 2001;27(1):34-6.

69. Fujita M, Mann T, Mann O, Berg D. Surgical pearl: use of nerve blocks for botulinum toxin treatment of palmar-plantar hyperhidrosis. J Am Acad Dermatol. 2001;45(4):587-9.

70. Levit F. Simple device for treatment of hyperhidrosis by iontophoresis. Arch Dermatol. 1968;98(5):505-7.

71. Nagar R, Sengar SS. A simple user-made iontophoresis device for palmoplantar hyperhidrosis. J Cutan Aesthet Surg. 2016;9(1):32-3.

72. Thomas L, Fatah S, Carmichael AJ. Tap water iontophoresis may be ineffective for axillary hyperhidrosis. Clin Exp Dermatol. 2015;40(3):337-8.

73. Hill AC, Baker GF, Jansen GT. Mechanism of action of iontophoresis in the treatment of palmar hyperhidrosis. Cutis. 1981;28(1):69-70, 2.

74. Wang L, Hilliges M, Gajecki M, Marcusson JA, Johansson $\mathrm{O}$. No change in skin innervation in patients with palmar hyperhidrosis treated with tap-water iontophoresis. $\mathrm{Br} \mathrm{J}$ Dermatol. 1994;131(5):742-3.

75. Anliker MD, Kreyden OP. Tap water iontophoresis. Curr Probl Dermatol. 2002;30:48-56.

76. Karakoc Y, Aydemir EH, Kalkan MT, Unal G. Safe control of palmoplantar hyperhidrosis with direct electrical current. Int J Dermatol. 2002;41(9):602-5.

77. Stolman LP. Treatment of excess sweating of the palms by iontophoresis. Arch Dermatol. 1987;123(7):893-6.

78. Chia HY, Tan AS, Chong WS, Tey HL. Efficacy of iontophoresis with glycopyrronium bromide for treatment of primary palmar hyperhidrosis. J Eur Acad Dermatol Venereol. 2012;26(9):1167-70.

79. Gujjar $\mathrm{M}$, Banga AK. Iontophoretic and microneedle mediated transdermal delivery of glycopyrrolate. Pharmaceutics. 2014;6(4):663-71.

80. Abell E, Morgan K. The treatment of idiopathic hyperhidrosis by glycopyrronium bromide and tap water iontophoresis. $\mathrm{Br} \mathrm{J}$ Dermatol. 1974;91(1):87-91.

81. Askari S, Glaser DA, King RM, Oliver D. Comparison of tap water iontophoresis to iontophoresis with glycopyrrolate. J Am Acad Dermatol. 2008;58(2):AB32. doi:10.1016/j.jaad.2007.10.156.

82. Lupin M, Hong HC, O'Shaughnessy KF. Long-term efficacy and quality of life assessment for treatment of axillary hyperhidrosis with a microwave device. Dermatol Surg. 2014;40(7):805-7.

83. Yarker YE, Goa KL, Fitton A. Oxybutynin. A review of its pharmacodynamic and pharmacokinetic properties, and its therapeutic use in detrusor instability. Drugs Aging. 1995;6(3):243-62.

84. Appell RA, Chancellor MB, Zobrist RH, Thomas H, Sanders SW. Pharmacokinetics, metabolism, and saliva output during transdermal and extended-release oral oxybutynin administration in healthy subjects. Mayo Clin Proc. 2003;78(6):696-702.

85. Davila GW, Daugherty CA, Sanders SW, Transdermal Oxybutynin Study G. A short-term, multicenter, randomized double-blind dose titration study of the efficacy and anticholinergic side effects of transdermal compared to immediate release oral oxybutynin treatment of patients with urge urinary incontinence. J Urol. 2001;166(1):140-5.

86. Goldfischer ER, Sand PK, Thomas H, Peters-Gee J. Efficacy and safety of oxybutynin topical gel 3\% in 
patients with urgency and/or mixed urinary incontinence: a randomized, double-blind, placebo-controlled study. Neurourol Urodyn. 2015;34(1):37-43.

87. Schick CH, Grallath T, Schick KS, Hashmonai M. Radiofrequency thermotherapy for treating axillary hyperhidrosis. Dermatol Surg. 2016;42(5):624-30.

88. Kim M, Shin JY, Lee J, Kim JY, Oh SH. Efficacy of fractional microneedle radiofrequency device in the treatment of primary axillary hyperhidrosis: a pilot study. Dermatology. 2013;227(3):243-9.

89. Fatemi Naeini F, Abtahi-Naeini B, Pourazizi M, Nilforoushzadeh MA, Mirmohammadkhani $M$. Fractionated microneedle radiofrequency for treatment of primary axillary hyperhidrosis: a sham control study. Australas J Dermatol. 2015;56(4):279-84.

90. Abtahi-Naeini B, Naeini FF, Saffaei A, Behfar S, Pourazizi M, Mirmohammadkhani $M$, et al. Treatment of primary axillary hyperhidrosis by fractional microneedle radiofrequency: is it still effective after long-term follow-up? Indian J Dermatol. 2016;61(2):234.

91. Letada PR, Landers JT, Uebelhoer NS, Shumaker PR. Treatment of focal axillary hyperhidrosis using a long-pulsed Nd:YAG $1064 \mathrm{~nm}$ laser at hair reduction settings. J Drugs Dermatol. 2012;11(1):59-63.
92. Bechara FG, Georgas D, Sand M, Stucker M, Othlinghaus $\mathrm{N}$, Altmeyer $\mathrm{P}$, et al. Effects of a long-pulsed 800-nm diode laser on axillary hyperhidrosis: a randomized controlled half-side comparison study. Dermatol Surg. 2012;38(5):736-40.

93. Leclere FM, Moreno-Moraga J, Alcolea JM, Vogt PM, Royo J, Cornejo P, et al. Efficacy and safety of laser therapy on axillary hyperhidrosis after one year follow-up: a randomized blinded controlled trial. Lasers Surg Med. 2015;47(2):173-9.

94. Nestor MS, Park H. Safety and efficacy of micro-focused ultrasound plus visualization for the treatment of axillary hyperhidrosis. J Clin Aesthet Dermatol. 2014;7(4):14-21.

95. Commons GW, Lim AF. Treatment of axillary hyperhidrosis/bromidrosis using VASER ultrasound. Aesthetic Plast Surg. 2009;33(3):312-23.

96. Heinig B, Koch A, Wollina U. Palmar hyperhidrosis treated by noninvasive ultrasound stellate ganglion block. Wien Med Wochenschr. 2016:1-4. doi: 10. 1007/s10354-016-0468-8.

97. Solish N, Bertucci V, Dansereau A, Hong HC, Lynde C, Lupin M, et al. A comprehensive approach to the recognition, diagnosis, and severity-based treatment of focal hyperhidrosis: recommendations of the Canadian Hyperhidrosis Advisory Committee. Dermatol Surg. 2007;33(8):908-23. 